to transmission experiments on waves shorter than 300 metres. Gradually widely scattered amateurs began to overhear signals exchanged between two very distant colleagues. In 1921, American amateurs transmitted to British amateurs on wavelengths of 200 metres; this was reciprocated in 1922. Meanwhile the American amateurs had found shorter waves better, and in 1923 were communicating easily with other amateurs across world-wide ranges. The first commercial application was made in the autumn of 1923 and has been followed by universal adoption of short-wave signalling. It is a remarkable example of a revolution in method which was not due to, and did not require, any change of technique-a revolution effected by pure discovery.

\title{
The Concept of Space.
}

$\mathrm{O}^{\mathrm{N}}$ Friday, June 6, Nottingham was honoured by a visit from Prof. A. Einstein, who delivered a lecture (in German) in the Great Hall of the University College. After each section an English translation was given by Dr. H. L. Brose. The chair was taken by Prof. H. H. Turner. The lecture was an account of the history of the concept of space, and was addressed to a general audience. At the end questions were invited: those received were all concerned with the present position of the unitary field theory. For the following impression of the lecture I am deeply indebted to Miss Dallas and Miss Lieber for their help, but for any inaccuracies I alone am responsible.

At the outset Prof. Einstein emphasised that he was not making an authoritative pronouncement, but merely stating his own personal opinions. He believed that the fundamental concept of physics was that of the rigid body. The idea of space was not acquired until a much later date, and was not known to the ancient Greeks. Euclid's geometry, in particular the part dealing with the congruence of triangles, was based upon notions of rigid bodies, such as measuring rods which could be moved about as a standard of comparison. Motion appeared first, not as in space, but as that of one body relative to another. The concept of space was introduced by Descartes, the founder of co-ordinate geometry. This was a purely mathematical notion, without any physical implications, and concerned only with the geometrical aspect of the relative position of two or more bodies. The other aspect of space was due to Newton, who considered the bodies, not at rest, but in motion. To deal with the problem of acceleration he introduced the idea of an absolute space, forming a framework by which the motion of the bodies could be measured, but itself quite unaffected by those bodies. It was a wonderful thing that Newton's genius enabled him to realise the definitely physical reality of space. This reality has been neglected or misunderstood by many of his successors, including the philosopher Kant.

However, in Prof. Einstein's opinion, the really decisive change from the geometrical to the physical conception of space was due to Faraday and Maxwell, who considered electromagnetic phenomena to have their seat in the ether, and spoke of the field or the state of this ether as affected by electromagnetic action. Why did they think it necessary to use a new word ether, when the old one space was already available? The reason, no doubt, was that they were fettered by the ideas prevailing in their day, and had not realised the connexion between the space of geometry and the space of physics. As material bodies were the first objects to be considered in physics, they introduced the idea of a material ether to replace what was formerly considered as empty space, through which electromagnetic action took place. This idea was developed by Lorentz, in whose view all electro. magnetic action, even that in the interior of material bodies, really took place in the ether. Thus he deprived matter of all its electromagnetic properties, but to compensate for this he deprived ether of all its mechanical properties, and attributed a capacity for motion only to the elementary particles of matter.

The next modification was the special theory of relativity. Classical physics used three co-ordinates in space and one in time. It was now found necessary to unite these into the four co-ordinates of space-time, and to give up the belief that events could be divided into categories of 'before', 'simultaneous', and 'after'. This prepared the way for the general theory of relativity, which dealt with the phenomena of inertia and derived the laws of motion from the geometrical structure of space, or rather of space-time, thus uniting geometry and physics in a new intimacy. The experimental verification of this theory is well known. We have now come to the conclusion that space is the primary thing and matter only secondary ; we may say that space, in revenge for its former inferior position, is now eating up matter.

With regard to the unitary field theory, the purpose of which was to derive all physical phenomena, electromagnetic as well as gravitation, from the properties of space, Prof. Einstein confessed that his colleagues did not agree with him. In fact, he added with a smile, they think that I am crazy on this subject. However, he himself had faith that the idea (which came to him during a severe illness two years ago) of attributing direction as well as metrical structure to space would ultimately lead to success in obtaining a single theory to embrace all phenomena. He regarded this as a true physical theory, not as a mere mathematical curiosity. It was best to leave aside the difficulties of the quantum theory for the present, but he hoped that when the simpler problem of

$$
\text { No. 3163, VoL. 125] }
$$


matter in bulk was solved the more difficult ones relating to atomic physics could speedily be dealt with. The urgent thing at present was to obtain the equations of motion of an electron or proton. Although the theory was not yet finished, he firmly believed that the end was very near.
Amid enthusiastic cheers, Alderman Huntsman, chairman of the College Council, announced that the blackboard used by Prof. Einstein and signed by him would be varnished and preserved in memory of a historic occasion.

H. T. H. Piaggio.

\section{Obituary.}

Prof. K. J. P. Orton, F.R.S.

$\mathrm{H}^{\mathrm{IS}}$ $\mathrm{S}$ friends even now find it more than a little difficult to realise that they have looked their last on Kennedy Orton-his vigour and freshness of mind and body, his keenness in attack on any problem, scientific or administrative, had suffered so little diminution with the passing of the years, that those who knew him well looked forward with no thought of the end to that stimulating interchange of ideas, to those talks ranging from China to Peru, which now are fated to remain but cherished memories.

Orton was a born man of science. Intended for a medical career, he found that the microscopical work involved was likely to prove too severe a tax on his eyesight, and he turned to the study of pure chemistry. As a scholar of John's he worked at Cambridge from 1891 to 1895 under Liveing, afterwards proceeding to Heidelberg, where he took his doctor's degree summa cum laude. Victor Meyer's attractive personality left a deep mark on Orton's character, and one is tempted to speculate on the rapidity of thought, the energy and versatility, the power to pick out underlying resemblances from surface differences, the single-hearted devotion to the pursuit of knowledge for its own sake, which were common characteristics in the mentalities of master and scholar.

$\mathrm{He}$ returned to London master of a wide range of chemical philosophy, and already interested in the properties of and mechanism of substitution in halogen compounds of benzene derivatives; well versed in laboratory technique ; a skilled worker in glass. In truth, he always retained keen interest in carefully planned and neatly executed laboratory work, and if ever he showed appreciation of his own powers it was when, with justifiable pride, he recalled instances of the evolution of skilful and enthusiastic researchers from distinctly unpromising material.

For six years he worked as demonstrator in chemistry at St. Bartholomew's Hospital, and in 1903 he was appointed to succeed Dr. J. J. Dobbie in the chair of chemistry in the University College of North Wales. The deep and accurate knowledge, the administrative ability, the sympathy for, and understanding of the student mind that he brought to his task at Bangor are well known to those whose good fortune it was to serve with him or to be taught by him, and his election to the Royal Society in 1921 testified equally to the value of his own researches and to the influence of the school of chemistry which he directed.

Orton's output of research was large-the general index of the Journal of the Chemical Society marks sixty-two titles under his name between 1897 and 1922. Looking over these and his later papers, one is struck by the clearness of their outlook-there is a refreshing absence of ragged edges, of untidiness or diffuseness of thought, diction, or method. The problem is clearly stated, attacked by well-planned experiments, and the result, positive, negative, or doubtful, is set out in vigorous language free from the slightest trace of ambiguity.

Substitution in aromatic compounds, and the problems involved in the theory of the intra-molecular migration of atoms had early occupied his attention, and during his time in London he had, in conjunction with Chattaway, attacked such problems as the substituted nitrogen chlorides and their rôle in the halogenation of anilides and anilines. About this period, too, his work on the action of light on nitrogen iodide shows his interest-an interest which never left him-in the efficacy of light in promoting chemical change.

A remarkable research, carried out at Bangor, showed that the migration of halogen in substituted acyl-anilides is dependent on the intermediate liberation of chlorine,

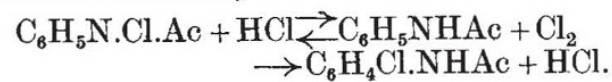

This work threw great light on the mechanism of the reaction, and confirmed Armstrong's general view that hydrochloric acid is the catalyst. Orton turned again and again to the consequences of this work, developing therefrom a method for the regulated chlorination of aromatic substances, and for the production of an acetic acid solution of known chlorine-concentration.

In collaboration with his students he carried out much valuable work, involving studies of the mechanism of acetylation and of halogenation, on acetic acid and acetic anhydride. He consistently applied physico-chemical methods to the elucidation of the mechanism of organic reaction, and in some of his later work turned to the more purely physical side of his science, as is shown by his development with $\mathrm{D}$. C. Jones of the technique of work on the mutual miscibility of liquids and of the determination of critical solution temperatures of ternary mixtures as a criterion of purity.

Orton was, however, much more than a chemist, and any survey of his activities limited to the chemical side of his life's work would present but a warped view of his character. His busy life left him but scant leisure, and the greater part of such spare time as he could command was devoted to

No. 3163, VoL. 125] 